\title{
UVA exposure of human skin reconstructed in vitro induces apoptosis of dermal fibroblasts: subsequent connective tissue repair and implications in photoaging
}

\author{
Françoise Bernerd ${ }^{1,2}$ and Daniel Asselineau ${ }^{1}$ \\ 1 L'Oréal, Life Sciences Research, C. Zviak Centre, 90 rue du général Roguet, \\ 92583 Clichy, France. Fax: 33-1-47-56-79-65. \\ 2 corresponding author: F. Bernerd, L'Oréal, Life Sciences Research, C. Zviak \\ Centre, 90 rue du général Roguet, 92583 Clichy, France. \\ Fax: 33-1-47-56-79-65
}

Received 18.02.98; revised 14.04.98; accepted 21.05.98

Edited by M. Piacentini

\begin{abstract}
The skin reconstructed in vitro has been previously shown to be a useful model to investigate the effects of UVB exposure (Bernerd and Asselineau, 1997). The present study describes the response to UVA irradiation. Major alterations were observed within the dermal compartment. Apoptosis of fibroblasts located in the superficial area of the dermal equivalent was observed as soon as $6 \mathrm{~h}$ after irradiation, leading to their disappearance after $48 \mathrm{~h}$. This effect was obtained without major alterations of epidermal keratinocytes suggesting a differential cell type sensitivity to UVA radiations. In addition, collagenase I was secreted by dermal fibroblasts. The UVA dermal effects could be observed even after removal of the epidermis during the post irradiation period, demonstrating that they were independent of the keratinocyte response. The analysis of the tissue regeneration during the following 2 weeks revealed a connective tissue repair via fibroblasts proliferation, migration and active synthesis of extracellular matrix proteins such as fibronectin and procollagen I. This cellular recolonization of the superficial part of the dermal equivalent was due to activation of surviving fibroblasts located deeply in the dermal equivalent. The direct damage in the dermis and the subsequent connective tissue repair may contribute to the formation of UVA-induced dermal alterations.
\end{abstract}

Keywords: skin equivalent; UVA radiation; dermal alterations; skin morphogenesis; photoaging

\footnotetext{
Abbreviations: UV, ultraviolet; UVB, $280-320$ nm; UVA, $320-$ $400 \mathrm{~nm}$; UVA1, 340-400 nm; FITC, fluorescein isothiocyanate; TUNEL, terminal deoxynucleotidyl transferase (TdT)-mediated dUTP nick end labeling; SBC, sunburn cell; BED, biologically efficient dose; MED, minimal erythemal dose; MMP1, matrix metalloproteinase I or interstitial collagenase; BrdU, bromodeoxyuridine
}

\section{Introduction}

UV exposure of skin leads to short term responses (erythema, sunburn and suntan) as well as long term effects, such as skin cancers and photoaging. Solar UV light comprises UVB wavelengths $(290-320 \mathrm{~nm})$ and UVA wavelengths (320$400 \mathrm{~nm}$ ), which represent the majority of UV radiations reaching earth. Although UVA wavelengths are less energetic than UVB wavelengths, they seem to be implicated in UV-carcinogenesis (Freeman et al, 1987; Drobetsky et al, 1995; Robert et al, 1996). The role of UVA in the photoaging process has been suspected for several years because these radiations have high penetration properties (Gilchrest, 1989).

Analysis of photoaged skin revealed major changes in the deep compartment of the skin, i.e., the dermis, including a degradation of the connective tissue, a decrease in collagen content and the accumulation of degenerative elastic fibers corresponding to the so-called 'solar elastosis' (Gilchrest, 1989; Lavker, 1995; Lavker and Kligman, 1988; Oikarinen et al, 1985). This elastotic material not only comprises impaired elastin but also associated proteins, such as fibrillin, desmosin or fibronectin (Chen et al, 1986; Yaar and Gilchrest, 1995). Studies of sun exposed versus sun protected skin revealed dermal alterations (Berstein et al, 1996; Warren et al, 1991), but do not allow determination of the respective roles of UVB and UVA radiations. Induction of dermal actinic damages after chronic UVA exposures has been obtained using hairless mice (Kligman et al, 1985). Studies on fibroblast or keratinocyte cultures revealed that through the generation of oxidative species (Tyrell and Keyse, 1990), UVA induces a decrease in Epidermal Growth Factor (EGF) binding (Djavaheri-Mergny et al, 1994), a modification of phospholipid metabolism (Hanson and deLeo, 1990) and lipid peroxidation (Morlière et al, 1991; Moysan et al, 1995). In addition, UVA also leads to the production of extracellular degrading enzymes, stromelysin 1 and interstitial collagenase (Petersen et al, 1995; Sawamura et al, 1996; Scharffetter et al, 1991, 1993; Wlaschek et al, 1994, 1995).

The identification of early cellular markers of UVA effects on skin may provide key insights into the long term process of photoaging. Recent studies with human volunteers revealed that several days of UVA exposure induced slight dermal changes (Lavker et al, 1995a,b; Lowe et al, 1995). However, experimental chronic UV exposure are difficult to perform in humans for ethical reasons. On the other hand, conventional cell cultures do not reproduce accurate physiological conditions. Human skin reconstructed in vitro can be an alternative means. This three dimensional skin system includes a dermal equivalent, in which human fibroblasts have physiological properties closer to in vivo conditions compared to classical cultures 
systems (Coulomb et al, 1983; Nusgens et al, 1984). On this dermal support a full thickness epidermis can be reconstructed, that displays normal keratinocyte differentiation markers and horny layers (Asselineau et al, 1985; 1989). This skin model is suitable not only for evaluating the effects of pharmacological agents, such as retinoids (Asselineau et al, 1989; Asselineau and Darmon, 1995; Magnaldo et al, 1992) but also the response to environmental stimuli. This system was recently used to study the typical early DNA damages induced in epidermis by UVB as well as the subsequent recovery phase (Bernerd and Asselineau, 1997).

The present work shows the effect of UVA exposure on skin reconstructed in vitro. A complete time course of events was recorded. In contrast with the epidermal UVB response, UVA irradiation induced major damages within the dermal compartment, including apoptosis of superficial fibroblasts. A progressive recolonization of the upper dermis occurred afterwards through proliferation and migration of surviving fibroblasts located in deeper dermis. These cells also displayed a considerable increase in procollagen I and fibronectin synthesis.

\section{Results \\ UVA sources}

The absence of an UVB emission by the UVA1 and UVA sources was carefully checked as shown in Figure 1.

\section{Determination of the UVA Biologically Efficient Dose (BED)}

The BED is the minimal dose necessary to induce morphological or structural changes of the skin without leading to death of the tissue (Bernerd and Asselineau, 1997). Sham irradiated skin reconstructed in vitro displays a fully differentiated epidermis (Figure 2A) characterized by the formation of well structured horny layers. In histological sections, the dermal equivalent showed fibroblasts embedded in the collagen matrix. Total UVA BED was found to be $25 \mathrm{~J} / \mathrm{cm}^{2}$ (Figure $2 \mathrm{~B}$ ). The alterations were mostly observed in the dermal compartment $48 \mathrm{~h}$ post irradiation. As shown in Figure 2B the fibroblasts located in the superficial part of dermal equivalent disappeared after UVA treatment. When a higher UVA dose was delivered $\left(30 \mathrm{~J} / \mathrm{cm}^{2}\right)$, the upper layers of epidermis were also affected (Figure 2C). However the basal and suprabasal keratinocytes do not show histological modifications. Immunostaining of vimentin, a cytoskeleton protein constitutively expressed in fibroblasts (Lazarides, 1982), revealed the absence of vimentin positive cells in the upper part of the dermal equivalent after UVA irradiation (Figure 2D-F), confirming the deletion of fibroblasts in that area. Basal keratinocytes of the reconstructed epidermis also synthesize vimentin protein. As shown in Figure 2, UVA irradiation does not alter this immunostaining, which corresponds to unmodified basal epidermal layer on histological sections. UVA 1 irradiation obtained using UVASUN 3000, induced similar effects as UVA, but the minimal BED was determined to be $30 \mathrm{~J} / \mathrm{cm}^{2}$ (data not shown).
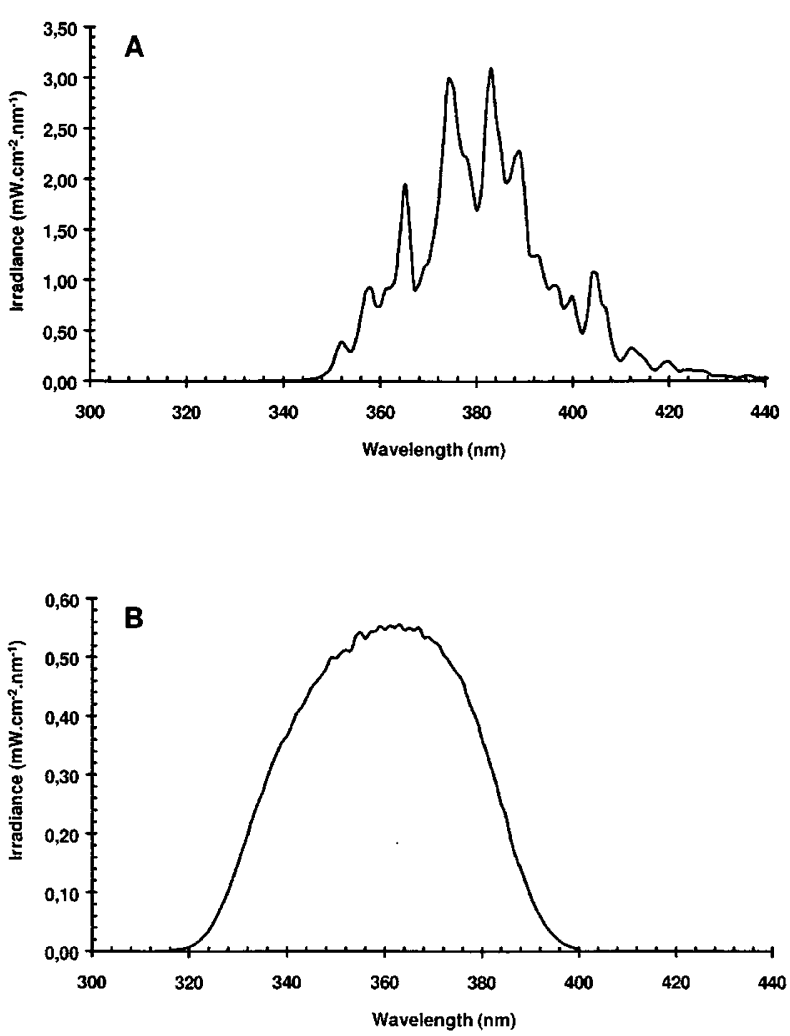

Figure 1 Spectra of UVA sources. (A) UVASUN spectrum: $340-440 \mathrm{~nm}$ (UVA1). (B) Solar simulator IDEM 300 spectrum, filtered with UG11 $1 \mathrm{~mm}$ and WG335 3 mm: $320-400 \mathrm{~nm}$ (UVA)

\section{Apoptotic process}

TUNEL reaction performed on samples obtained $6 \mathrm{~h}$ after BED-UVA exposure revealed clearly positive fibroblasts in the superficial zone of the dermal equivalent compared to a sham-irradiated sample (Figure 3). Only a few granular keratinocytes had a higher signal after UVA exposure (Figure 3B). Even 24 to $48 \mathrm{~h}$ after UVA exposure, TUNEL reaction remains negative in basal and suprabasal epidermal keratinocytes (data not shown).

\section{Epidermal alterations}

The global architecture of the epidermis was not significantly altered 24 to $48 \mathrm{~h}$ after UVA exposure. Histologically, the uppermost epidermal cells displayed some morphological alterations at $30 \mathrm{~J} / \mathrm{cm}^{2}$ total UVA exposure (Figure $2 \mathrm{C}$ ). Immunostainings using specific antibodies directed against keratinocyte differentiation proteins, such as keratin 10, involucrin, filaggrin, loricrin and keratinocyte transglutaminase were performed. The only modification observed at the UVA-BED concerned the subcellular localization of loricrin reactivity. Normally detected at the cell periphery (Figure 4A), UVA irradiation induced a wider distribution within the cytoplasm of keratinocyte (Figure 4B). 
UVA $(320-400 \mathrm{~nm})$
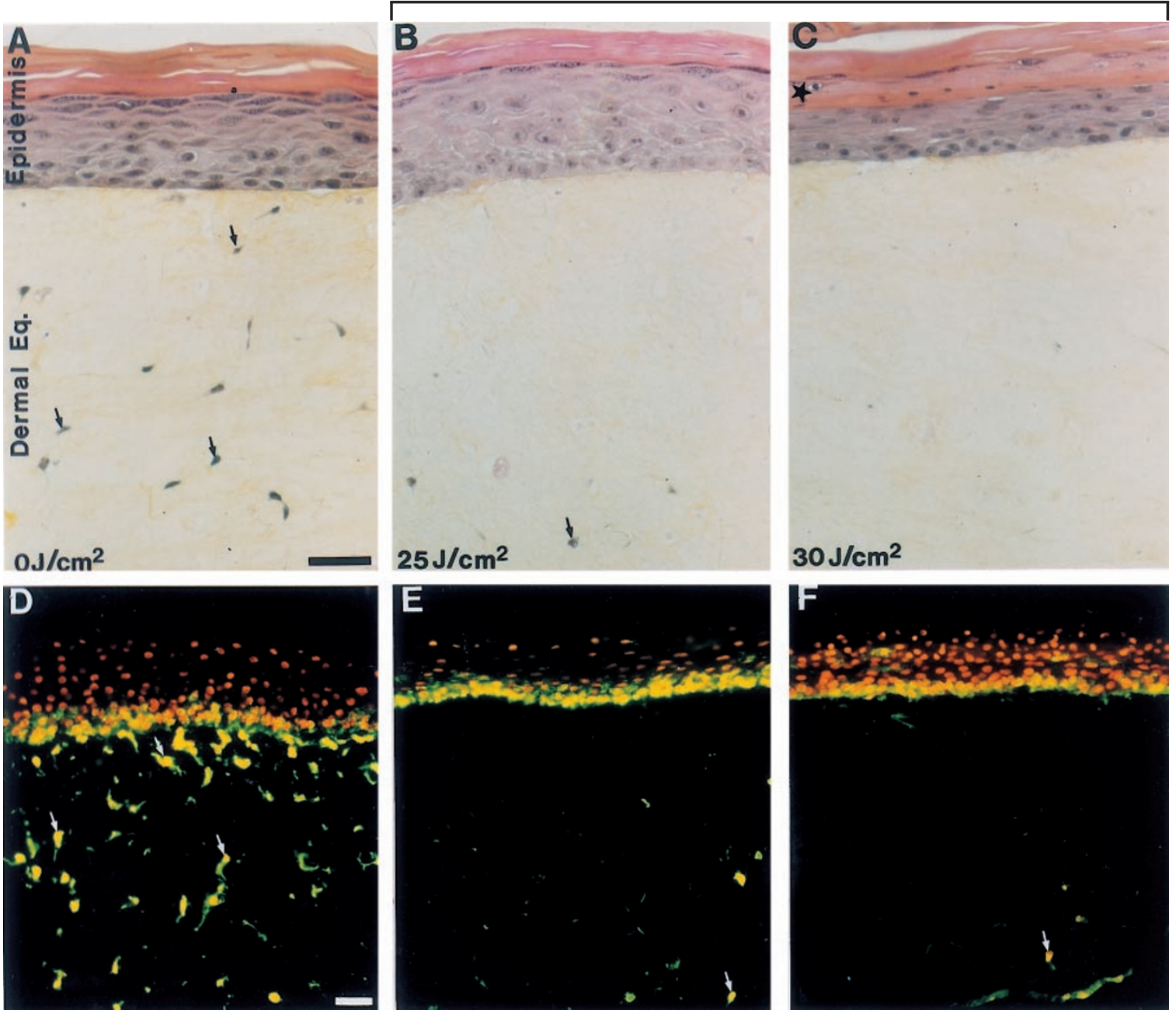

Figure 2 UVA-BED effect on skin reconstructed in vitro 48 h after exposure. (Solar simulator source, UVA $320-400 \mathrm{~nm}$ ). (A-C) Histology; (D-F) Immunolabelling using anti vimentin antibody. (A,D) Sham-irradiated sample. (B,E) UVA $25 \mathrm{~J} / \mathrm{cm}^{2}$. (C,F) UVA $30 \mathrm{~J} / \mathrm{cm}^{2}$. Note that the UVA-BED is $25 \mathrm{~J} / \mathrm{cm}^{2}$. This dose induces the disappearance of superficial fibroblasts in the dermal equivalent (arrows), without major alterations in the epidermis. At $30 \mathrm{~J} / \mathrm{cm}^{2} \mathrm{UVA}$, the epidermis is slightly affected in the upper layers (star), and parakeratosis is observed. Scale is $50 \mu \mathrm{m}$

\section{Typical UVB damages were not significantly induced by UVA irradiation}

A classical UVB effect is the sunburn cell (SBC) formation in the epidermis $24 \mathrm{~h}$ after exposure (Young, 1987). UVA BED failed to induce SBC formation (data not shown). The induction of pyrimidine dimers was also analyzed by immunostaining using $\mathrm{H} 3$ monoclonal antibody. After $30 \mathrm{~J} / \mathrm{cm}^{2}$ total UVA, a weak positive signal was found (Figure 5C). However, the intensity of the fluorescence was far weaker compared to a control sample irradiated with $50 \mathrm{~mJ} / \mathrm{cm}^{2}$ UVB (Figure 5B). No fluorescence was observed after UVA1 irradiation (data not shown).

\section{The effect of UVA exposure is due to the physical penetration properties of UVA radiation}

UVA irradiation preferentially affected the superficial fibroblasts and spared the deeper ones. These observa- tions raised these questions: (i) what is the role of the penetration properties of UVA? and (ii) what is the influence of medium proximity for deep fibroblasts? (the culture is on a grid fed by capillary action). To address these questions, dermal equivalents of different thickness were prepared by increasing the volume of initial collagenfibroblasts mixture (see Materials and Methods). The proportion of collagen and cells was kept constant, which allowed similar contraction kinetics and cell density. The reconstructed skins obtained were then UVA irradiated and analyzed by histology and vimentin immunochemistry. Irrespectively of the dermal equivalent thickness, the disappearance of superficial fibroblasts, its depth in the dermis, and the presence of surviving cells in the lower part of the dermis were found to be similar (Figure 6A and $B)$. The response seemed to be related to UVA penetration into the dermal compartment, the upper part of the dermis being more impaired than the deeper portion. 


\section{Epidermis does not play an essential role in the UVA dermal response}

Because the skin system is comprised of two living compartments and therefore allows signal exchanges between them, we wondered whether the dermal alterations after UVA exposure could be indirectly mediated by an epidermal response (i.e. soluble factors). Normal recon- structed skins in vitro were irradiated with UVA-BED and the epidermis removed immediately after irradiation. The samples were then kept for $48 \mathrm{~h}$ to allow the effects of UVA to develop. This procedure ensured that the dermis received the same dose of UVA. Figure 7 shows that UVA alterations on dermal fibroblasts were still observed in the absence of epidermis during the post irradiation period, suggesting that UVA dermal effects do not depend on an epidermal response.
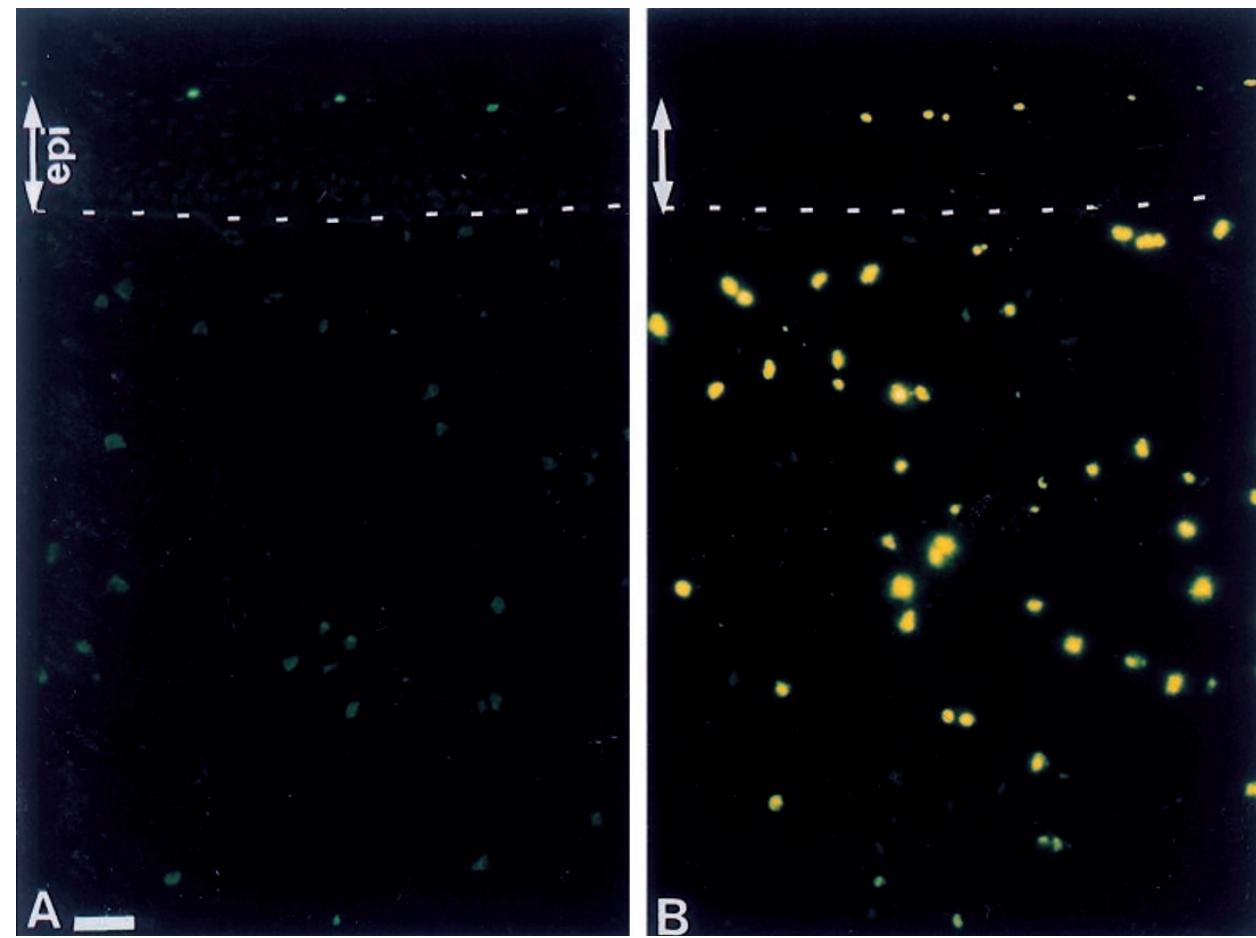

Figure 3 TUNEL assay on UVA irradiated reconstructed skin $6 \mathrm{~h}$ after exposure. (A) Sham irradiated skin; (B) $25 \mathrm{~J} / \mathrm{cm}^{2}$ UVA-irradiated skin. Note the presence of positive fibroblasts within the dermal equivalent after UVA irradiation $(320-400 \mathrm{~nm})$. Epi=epidermis. Scale is $50 \mu \mathrm{m}$
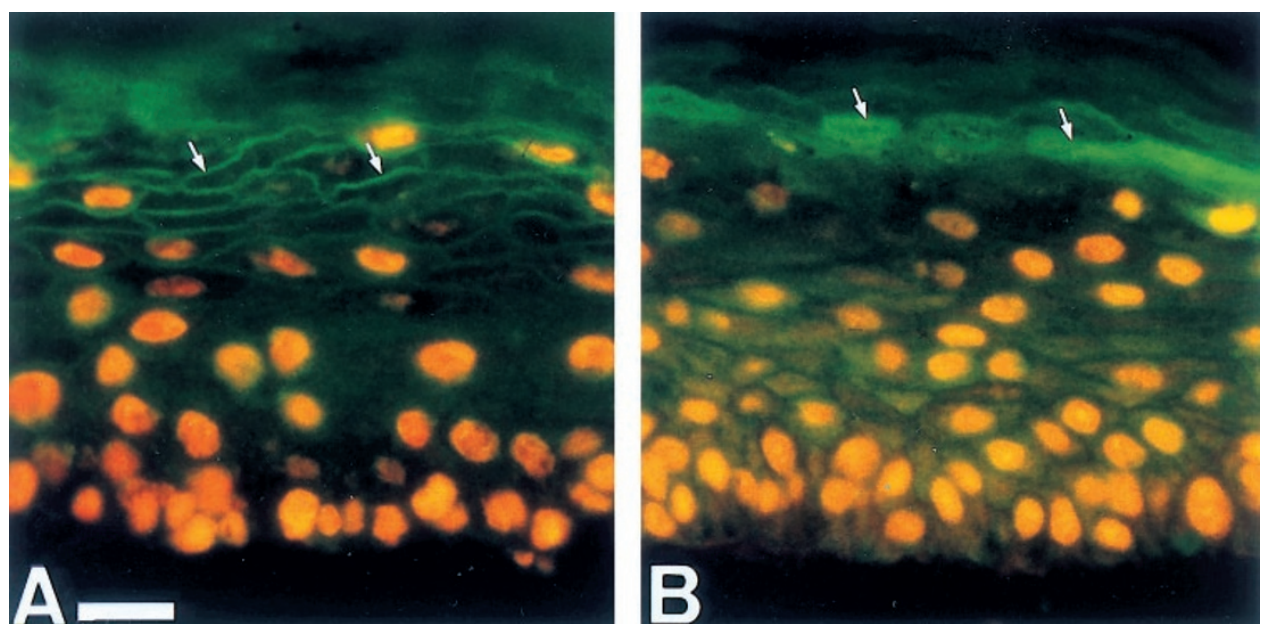

Figure 4 UVA irradiation induced subcellular redistribution of loricrin. Immunolabelling using anti loricrin antiserum. (A) Sham irradiated sample. (B) Sample irradiated with $30 \mathrm{~J} / \mathrm{cm}^{2}$ UVA $(320-400 \mathrm{~nm})$. Note that the classical loricrin peripheral staining of granular cells is cytoplasmic in the UVA exposed skin (arrows). Scale is $50 \mu \mathrm{m}$ 

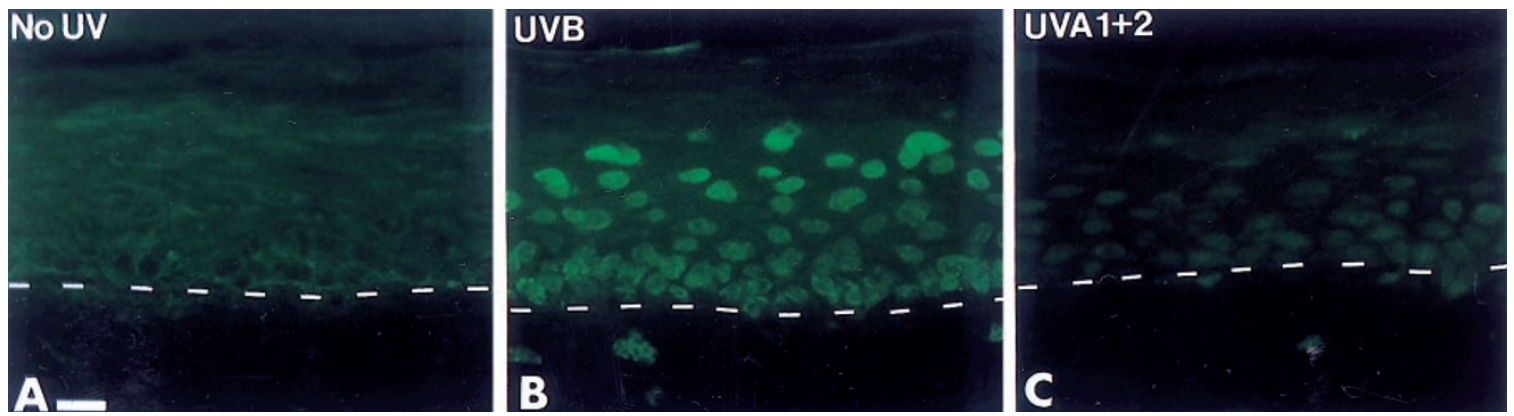

Figure 5 Absence of significant CPD induction after UVA irradiation. Immunodetection of pyrimidine dimers using H3 monoclonal antibody. (A) Sham-irradiated sample. (B) $50 \mathrm{~mJ} / \mathrm{cm}^{2}$ UVB-irradiated positive control. (C) $30 \mathrm{~J} / \mathrm{cm}^{2}$ UVA $(320-400 \mathrm{~nm}$ ) irradiated sample. The UVB positive control shows fluorescent nuclei. UVA exposed skin shows a very slight staining. Scale is $30 \mu \mathrm{m}$

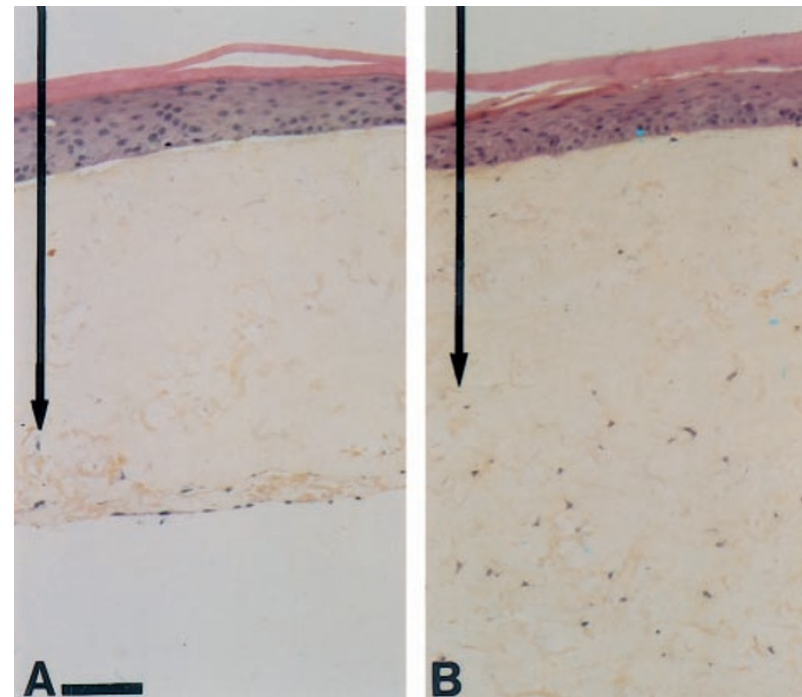

Figure 6 Biological assay of UVA effects in the dermal compartment. (A) Classical reconstructed skin composed of a $0.25 \mathrm{~mm}$ thick dermal equivalent (B) Reconstructed skin using a $0.80 \mathrm{~mm}$ thick dermal equivalent, $48 \mathrm{~h}$ afte $25 \mathrm{~J} / \mathrm{cm}^{2}$ UVA $(320-400 \mathrm{~nm})$. Note that the effects into the dermal compartment corresponds to approximately the same depth in all conditions, allowing the survival of the deepest fibroblasts. Scales are $100 \mu \mathrm{m}$

\section{Interstitial collagenase is a UVA dermal maker}

The secretion of MMP1 in culture medium after UVA irradiation was measured using ELISA assay. Figure 8A shows that UVA exposure induced an increase in the level of MMP1. The assay was also performed using samples from which the epidermis was removed immediately after UVA exposure and revealed a similar increase (Figure 8B), which suggests that the major part of MMP1 released in culture medium was produced by dermal fibroblasts.

\section{Dermal 'regeneration' occurred within 2 weeks after UVA exposure}

After UVA-BED exposure, a step by step dermal recovery takes place. The epidermis that was not significantly altered
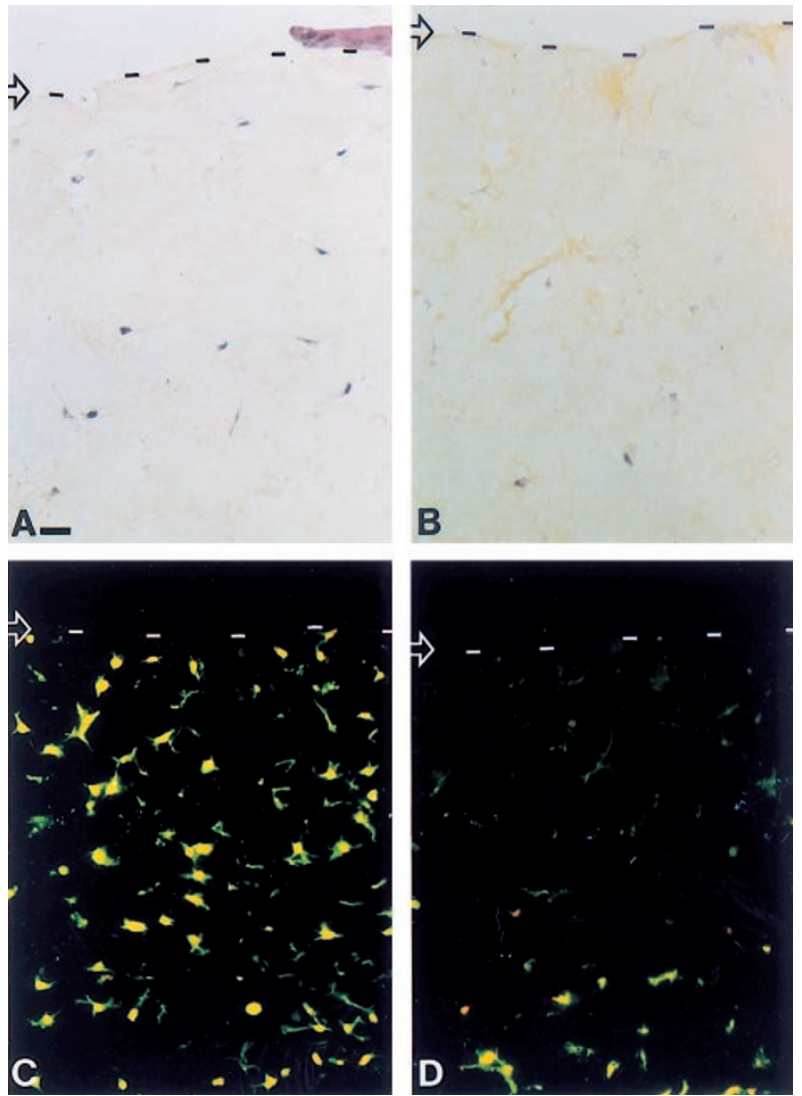

Figure 7 UVA dermal effects can be obtained independently of the epidermal response. The epidermis of the reconstructed skin has been removed immediately after UVA exposure. Histology $(\mathbf{A}, \mathbf{B})$ or immunolabelling using anti-vimentin antibody (C,D) have been performed $48 \mathrm{~h}$ after UVA irradiation $(320-400 \mathrm{~nm})$. (A,C) Sham irradiated sample. (B,D) $48 \mathrm{~h}$ after $25 \mathrm{~J} / \mathrm{cm}^{2}$ UVA. The disappearance of superficial fibroblasts is observed even in the absence of epidermis during the $48 \mathrm{~h}$ following UVA exposure. Scale is $30 \mu \mathrm{m}$

during the first $48 \mathrm{~h}$ did not show obvious further modifications. Interestingly, histological observations showed a progressive recolonization of superficial dermis by deeply located surviving cells. This process began with a progressive proliferation of deep fibroblasts and migration through the 

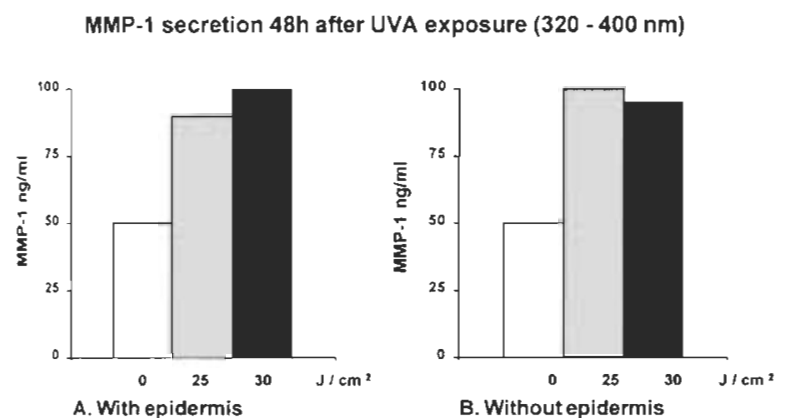

Figure 8 Interstitial collagenase ELISA assay. Culture media were collected $48 \mathrm{~h}$ after UVA irradiation $(320-400 \mathrm{~nm})$. The period post irradiation has been performed with epidermis (A) or without epidermis (B). The values represent the mean of three samples. The S.E.M. was less than $10 \%$ for all data

dermis from the deepest part to the top. After 10-14 days the dermal equivalent showed a similar cell density when compared to the sham-irradiated sample. Anti-vimentin immunostaining supported these histological observations (Figure 9). Forty-eight hours after UVA irradiation, the upper part of the dermis was devoid of fibroblasts and appeared as a negative zone just underneath the epidermis (Figure 9A and 8). On days 3, 4 and 7 this zone decreased in size (in depth), the deeper part of the dermis was recolonized before the uppermost part (Figure 9C-E). By day 10 (Figure 9F) and 14 (not shown) the whole dermis contained fibroblasts, suggesting that recolonization was achieved.

Proliferation of dermal fibroblasts was followed by BrdU incorporation. Positive dermal fibroblasts were not found in sham-irradiated samples (data not shown). In contrast, positive cells were identified 7 days after UVA exposure (Figure 10). Characterization of these recolonizing fibroblasts was assessed by immunostaining using antibodies directed against antigens of the extracellular matrix. An increase in the deposition of fibronectin and procollagen I was clearly detected in the dermal equivalent during the recolonization period (Figure 11).

\section{Discussion}

In a previous work, we demonstrated that skin reconstructed in vitro was suitable to study early damages due to a single UVB exposure (DNA lesions, keratinocyte apoptosis) and also subsequent alteration and recovery of the tissue (Bernerd and Asselineau, 1997). The present work focused on the response of reconstructed skin after either $25 \mathrm{~J} / \mathrm{cm}^{2}$ UVA or $30 \mathrm{~J} / \mathrm{cm}^{2}$ UVA1 irradiation, which is a dose close to the human UVA Minimal Erythemal Dose (MED) (Lavker et al, 1995a,b; Lowe et al, 1995). The first observation was that UVA failed to significantly induce the classical UVB damages. Sunburn cells were not found, and immunodetection of pyrimidine dimers (CPD) revealed only a weak signal after exposure to a full UVA spectrum $(320-400 \mathrm{~nm})$ and none after only UVA1. This is in agreement with the UV action spectrum of CPD induction, which showed a decreased efficiency with increasing wavelengths (>300 nm) (Freeman et al, 1989). Moreover, UVA is more efficient in inducing other DNA lesions deriving from oxidative stress, such as single or double strand breaks (Peak et al, 1987; Peak and Peak, 1991; Tyrell and Pidoux, 1989). The major tissue target of UVB was the epidermis resulting in significant alterations in the keratinocyte differentiation process. On the contrary, UVA exposure did not lead to drastic structural alterations of the epidermis, but only slight morphological changes within the upper layers. UVA induced a redistribution of subcellular localization of loricrin, from the cell periphery, where it is incorporated in the forming cornified envelope (Magnaldo et al, 1992; Steinert and Marekov, 1995), to the whole cytoplasm. It is tempting to relate this effect to UVA induction of cell membrane damages (Gaboriou et al, 1993). In addition, the results obtained during post irradiation time after the epidermis was removed suggests that keratinocytes are not required for the UVA dermal response.

The major result in the present study is that UVA effects are targeted to the dermis. Regarding the induction of the apoptotic process, keratinocytes are not affected by UVA, while superficial dermal fibroblasts are drastically altered, suggesting a differential cell type sensitivity to UVA radiation. Previous studies regarding the UVA-induced oxidative stress response indicated that fibroblasts offered less resistance than keratinocytes (Applegate et al, 1995; Morlière et al, 1991; Moysan et al, 1995; Niggli and Applegate, 1997). Additionally, keratinocytes express constitutively high levels of heme oxygenase-2 and ferritin (Applegate et al, 1995; Applegate and Frenk, 1995), which are involved in the defense response to oxidative stress (Vile and Tyrrell, 1993) and may increase the resistance of keratinocytes to UVA radiation. Considering the fact that keratinocytes also represent the most superficial cell type of our body, which is exposed to multiple external aggressions, it is tempting to hypothesize that they are genetically programmed for stress resistance. In that sense, the presence of high amounts of keratin polypeptides in the keratinocytes (Fuchs, 1996), as well as a normal keratinocyte differentiation program leading to cornified envelope formation (Reichert et al, 1993; Steinert and Marekov, 1995), may provide these cells with the appropriate equipment to build an efficient physical barrier.

The UVA delayed response corresponds to a dynamic process of recolonization of the dermis by spared fibroblasts from the deeper dermis. Skin reconstructed in vitro can thus be considered as a suitable model to study dermal fibroblasts responses. Several features of fibroplasia known to occur during in vivo wound repair are indeed found, such as fibroblast proliferation, migration, and new extracellular matrix deposition, like fibronectin and procollagen I (Clark, 1991). Interestingly, migrating fibroblasts exhibited an increased level of Keratinocyte Growth Factor (KGF) mRNA (data not shown), thus completing the phenotype of wound healing fibroblast (Werner et al, 1992). In addition, MMP 1 production after UVA exposure may facilitate the migration of fibroblasts inside the collagen matrix during the recolonization phase. Other studies showed secretion of matrix degrading enzymes after UVA irradiation (Petersen et al, 1995; Sharffetter et al, 1991). All together these results show that this 'simplified' dermis is able to 'regenerate', thus providing an attractive model for connective tissue repair in vitro. 
How can the UVA-induced alterations described in this study could be related to the photoaging process? Histological examination of photoaged skin reveals two distinct dermal zones. First, a subpapillary area called 'grenz zone' in human photoaged skin (Lavker, 1995) or 'repair zone' in animal models of photoaging (Kligman et al,
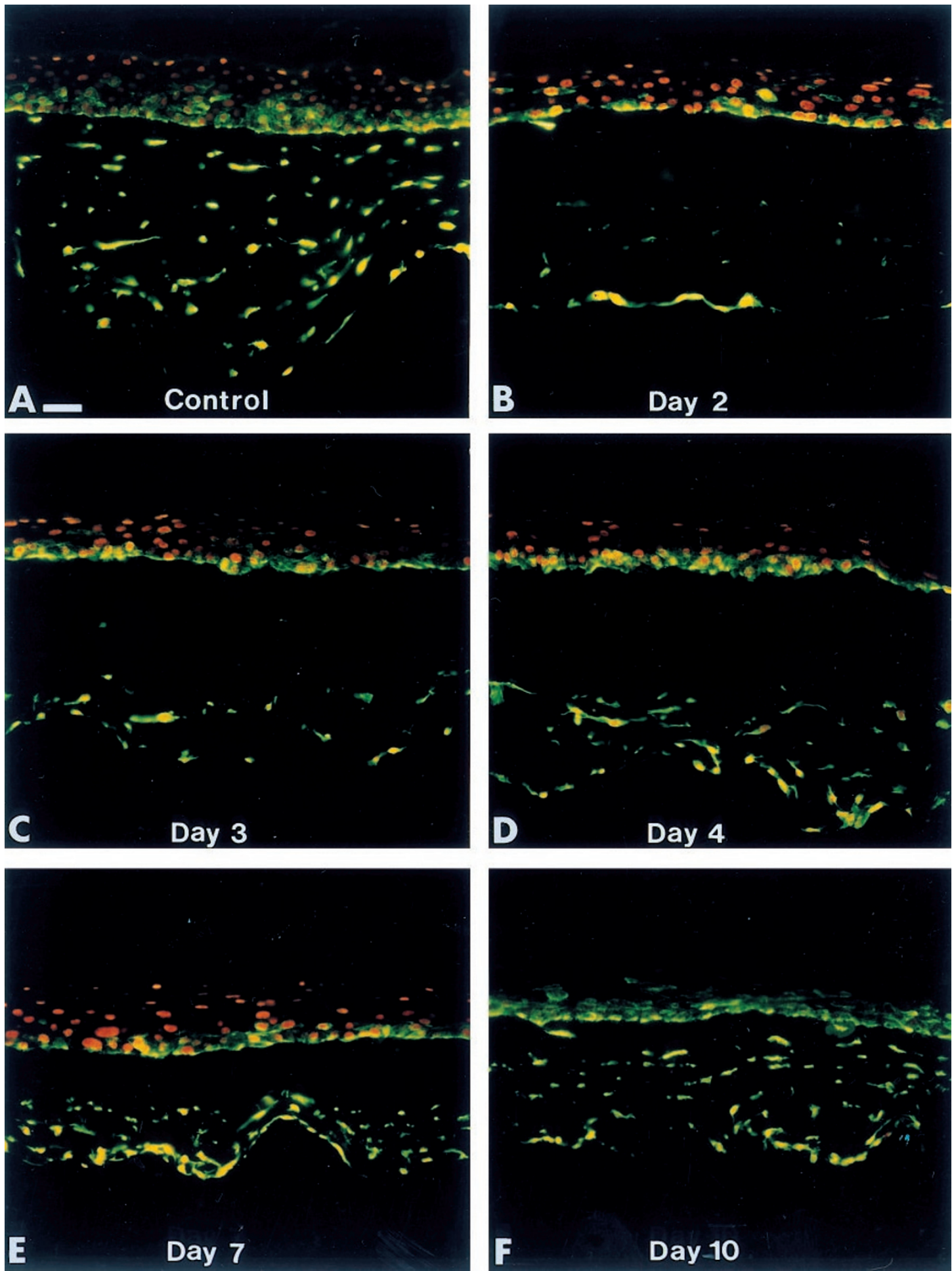

Figure 9 Recolonization of the superficial dermis by deep fibroblasts. Anti-vimentin immunostaining. (A) Sham irradiated sample. (B-F) Samples irradiated with $25 \mathrm{~J} / \mathrm{cm}^{2}$ UVA $(320-400 \mathrm{~nm}$ ) and observed up to 10 days after. The time (days) after the UVA exposure is indicated at the bottom. Note that the presence of vimentin positive fibroblasts in the dermal equivalent progressively increases from the bottom to the top. After 10 days the distribution of fibroblasts closely resembles that of the control. Scale is $60 \mu \mathrm{m}$ 

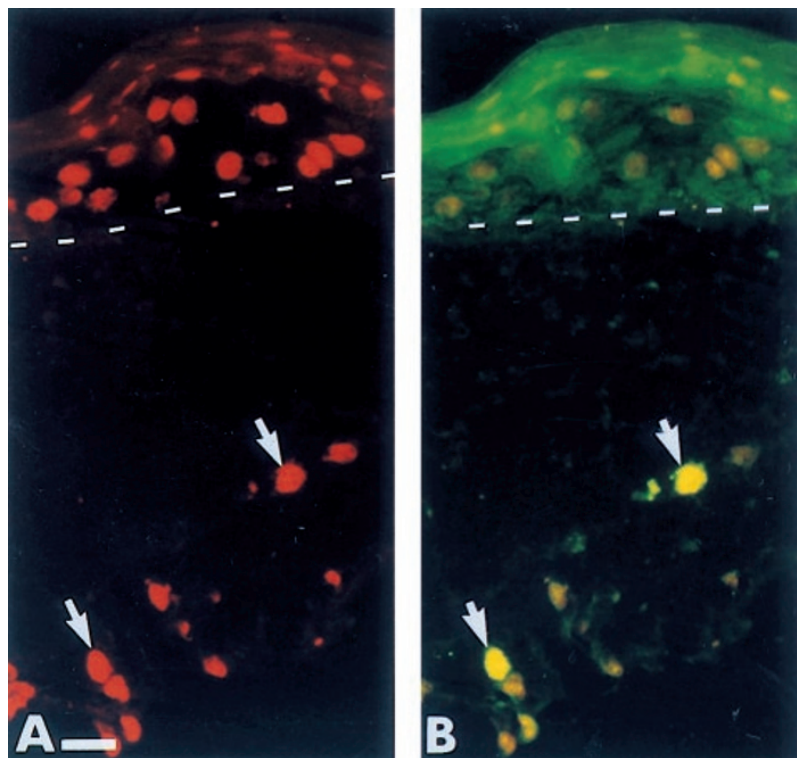

Figure 10 BrdU immunostaining 7 days after UVA exposure $(320-400 \mathrm{~nm}$, $25 \mathrm{~J} / \mathrm{cm}^{2}$ ). (A) Propidium iodide. (B) Anti-BrdU immunostaining. Note that positive nuclei are observed in deep fibroblasts recolonizing the dermal equivalent. Scale is $30 \mu \mathrm{m}$

1982); second, underneath this superficial area, a zone where elastotic material is present (Kligman, 1995; Lavker, 1995; Yaar and Gilchrest, 1995). In the in vitro reconstructed skin model, the disappearance of fibroblasts in the superficial dermis after UVA exposure could be correlated with the first zone that is progressively recolonized. To support this idea, in the in vivo subepidermal repair zone, a new connective tissue is formed when UV exposure stops, corresponding to de novo synthesis of collagen, elastin and fibronectin (Kligman et al, 1982, 1984; Schwartz and Kligman, 1995). This phenomenon has been compared to a wound healing process. The deeper part of dermal equivalent, which is characterized by the beginning of the recolonization process and a high deposition of fibronectin, may correspond to the location where elastotic material is produced in vivo. High levels of fibronectin have been detected in elastotic material in human photoaged skin (Chen et al, 1986), as well as after UVA irradiations in the mouse model (Boyer et al, 1992). The collagenase production could also contribute to the decrease in total collagen content that takes place during photoaging (Warren et al, 1991; Fisher et al, 1996).

Successive UVA-induced events described above (alterations followed by repair processes), may contribute to the histological feature of photoaged skin, especially with regard to the formation of 'grenz zone' and possibly the localization of elastotic material.

\section{Materials and Methods}

\section{Tissue culture}

Keratinocyte and fibroblast cultures Human epidermal keratinocytes were isolated from skin obtained after mammary reduction and cultured as described by Rheinwald and Green (1975) on a feeder layer of Swiss 3T3 fibroblasts. Human adult dermal fibroblasts were isolated after spreading from mammary skin explants prepared for isolation of epidermal keratinocytes. The 'FMD' strain of fibroblasts corresponds to the skin from a 16-year old person.

Reconstructed skin in vitro (Asselineau et al, 1985). Dermal equivalents (lattices) were prepared as described previously, except that we used 'FMD' cells (Bernerd and Asselineau, 1997). Normal sized lattices were prepared using $7 \mathrm{ml}$ of the collagenfibroblast mixture (containing $10^{6}$ cells) in a $60 \mathrm{~mm}$ petri dish. Thick lattices were respectively prepared using $7 \mathrm{ml}$ of the mixture and $10^{6}$ cells, $10 \mathrm{ml}$ and $1.4 \times 10^{6}$ cells, and $14 \mathrm{ml}$ and $2 \times 10^{6}$ cells in $35 \mathrm{~mm}$ petri dishes. The lattices were allowed to contract for 3 days. Adult human keratinocytes were seeded on this support and kept submerged for 7 days allowing the cells to form a monolayer. The cultures were then raised at the air-liquid interface on grids and kept 1 week to allow keratinocytes to stratify and differentiate completely.

\section{Irradiation sources}

UVA irradiations were performed using two different sources. A UVASUN 3000 (Mutzhas, Germany) was used to produce UVA1 $(340-400 \mathrm{~nm})$. A Solar simulator (Arcane, France) fitted with a 1000 Watts Xenon lamp filtered by a UG11 $(1 \mathrm{~mm})$ and a WG335 (3 mm) Schott filters delivered total UVA. UV spectra were carefully checked with an ORIEL Intaspec IV spectroradiometer.

Reconstructed skins on grids were irradiated without medium. Fresh medium was added after irradiation. Reconstructed skins were routinely incubated $1 \mathrm{~h}$ at $37^{\circ} \mathrm{C}$ in a medium containing $0.1 \mathrm{mg} / \mathrm{ml}$ bromodeoxyuridine (BrdU) (Boehringer Mannheim, Germany) before being fixed for histology or frozen in liquid nitrogen. The conditioned medium obtained 24 or $48 \mathrm{~h}$ after the irradiation was carefully collected for collagenase I assay.

\section{Histology}

Samples were fixed in 10\% neutral formalin and treated for histology. Paraffin sections were stained with hematoxylin, eosin, saffron.

\section{Immunostaining}

Antibodies Mouse monoclonal antibodies (Mab) were against human keratin 10 (RKSE 60, Sanbio Laboratories), filaggrin (Biomedical Technologies Inc, USA), keratinocyte transglutaminase (Biomedical Technologies Inc, USA), vimentin (Monosan, The Netherlands) and BrdU (Boehringer Mannheim, Germany) and thymine dimers (H3) (Dr. Roza, Netherlands) (Roza et al, 1988). A monoclonal rat anti human procollagen type I was purchased from Chemicon (USA). Rabbit polyclonal antibodies were against human involucrin (Biomedical Technologies Inc, USA), loricrin (Dr. Magnaldo, France), (Magnaldo et al, 1992), fibronectin (Pasteur Institute, France). FITC-conjugate rabbit anti-mouse immunoglobulins or FITC-conjugate swine anti-rabbit immunoglobulins (Dako, Denmark) were used as second antibodies.

Procedure Samples were embedded in Tissue Tek (Miles, USA), frozen in liquid nitrogen and $5 \mu \mathrm{m}$ vertical cryosections were prepared. Immunohistochemistry was performed as previously described (Bernerd and Asselineau, 1997). Detection of thymine dimers was carried out according to Roza et al (1991). Nuclear counterstaining using propidium iodide was carried out routinely. 
Control
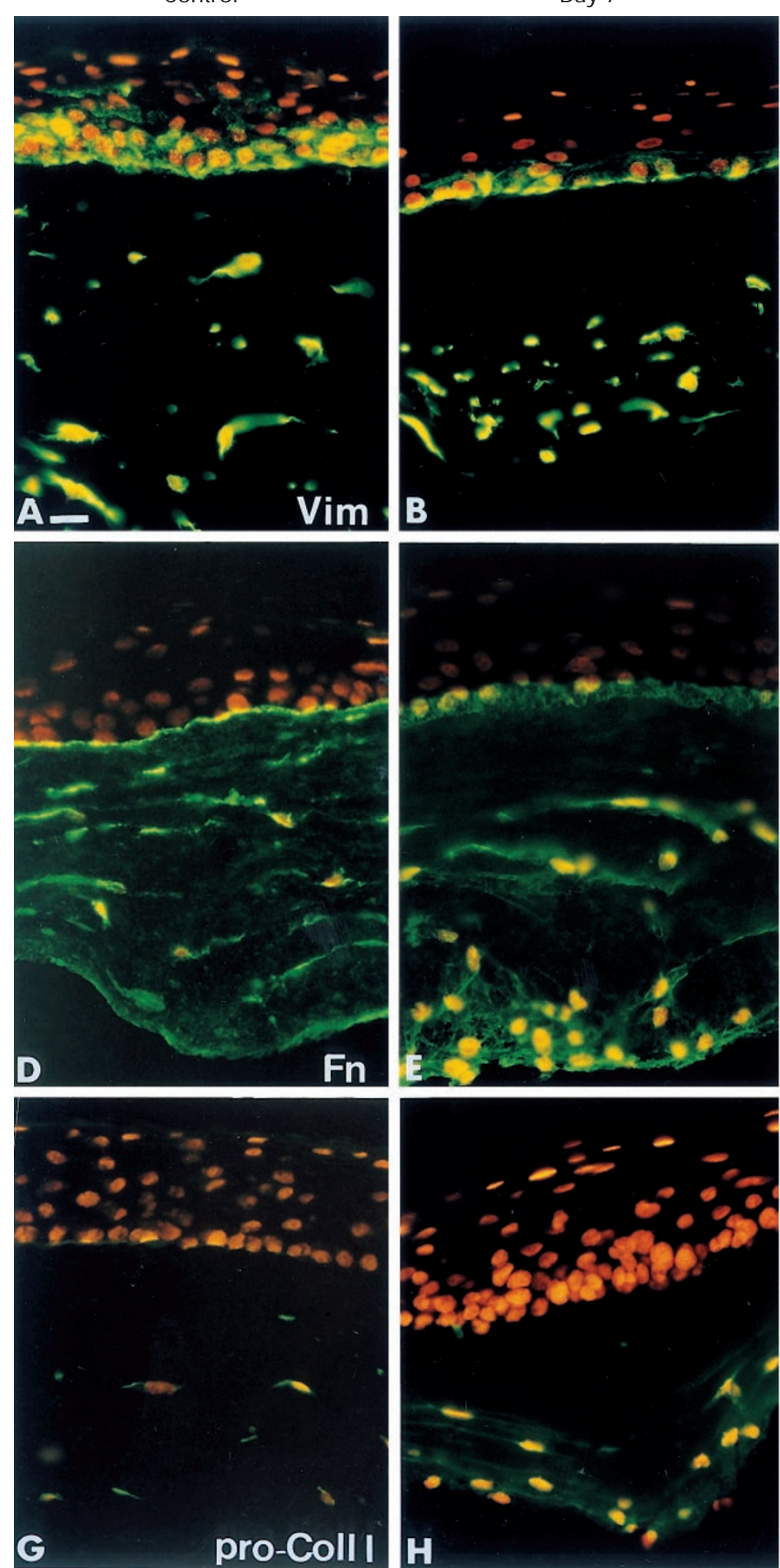

Day 7
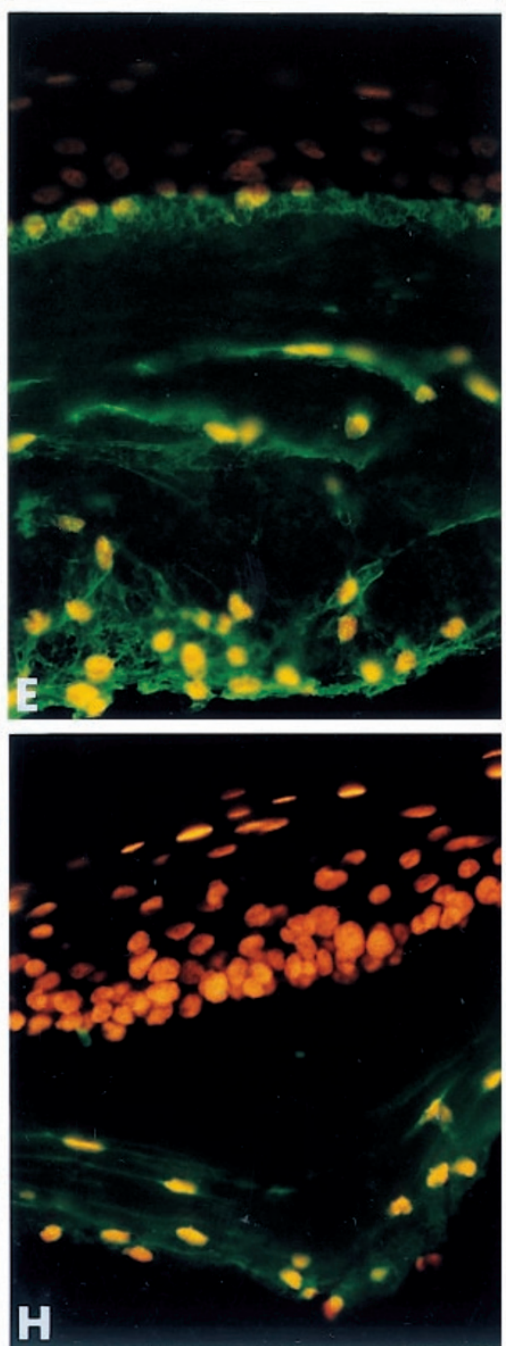

Day 14
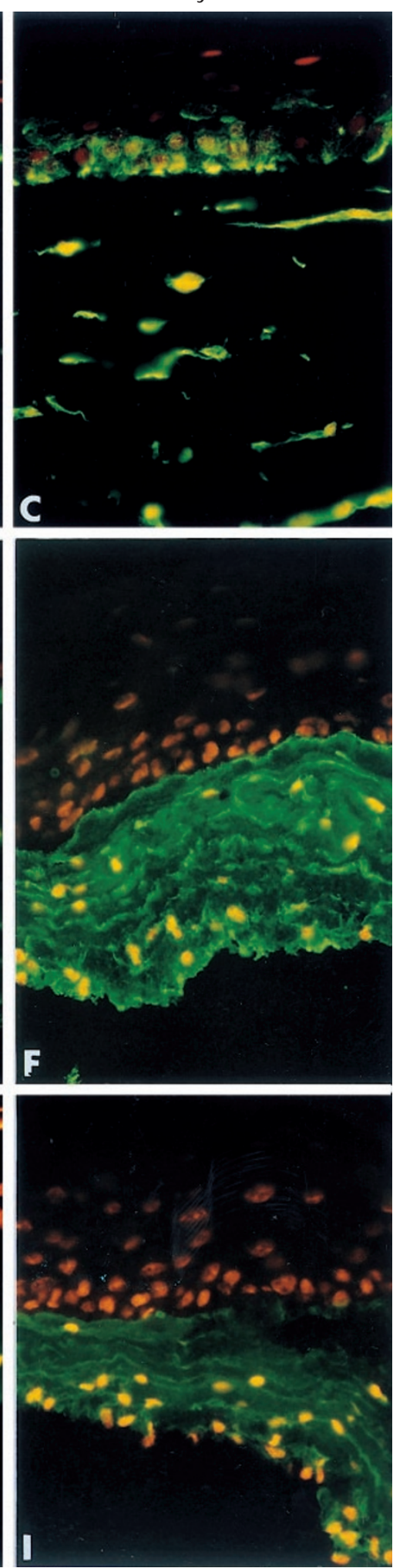

Figure 11 Characterization of recolonizing fibroblasts. (A-C) Anti-vimentin immunostaining (Vim); (D-F) Anti-fibronectin immunostaining (Fn). (G-I) Antiprocollagen I immunostaining (pro-Coll I). (A,D,G) Sham-irradiated samples observed at day 10. (B,E,H) $25 \mathrm{~J} / \mathrm{cm}^{2}$ UVA-irradiated ( $320-400 \mathrm{~nm}$ ) samples observed at day 7 . (C,F,I) $25 \mathrm{~J} / \mathrm{cm}^{2}$ UVA irradiated samples observed at day 14 . Note that fibronectin and procollagen I deposits are clearly more important in the dermal equivalents of irradiated samples, compared to sham-irradiated samples. Scale is $30 \mu \mathrm{m}$ 


\section{TUNEL method}

TUNEL reaction was performed as described (Bernerd and Asselineau, 1997) using the In Situ Cell Death Detection Kit (Boehringer Mannheim, Germany) on 4\% formaldehyde fixed frozen sections.

\section{MMP 1 assay}

The amount of secreted interstitital collagenase (MMP1) was assessed using the Biotrack MMP-1 human ELISA system (Amersham, England). Conditioned medium from sham-irradiated or UVA-irradiated reconstructed skin was collected either 24 or $48 \mathrm{~h}$ after the irradiation

\section{Proliferation estimation}

Positive cells labelled with anti-BrdU was analyzed using a fluorescent microscope.

\section{Acknowledgements}

We would like to thank Dr. T. Magnaldo for the generous gift of anti-loricrin antiserum, Dr. L. Roza for providing us with the $\mathrm{H} 3$ antibody. Miss $\mathrm{C}$. Vioux is acknowledged for expert technical assistance. We also thank Miss C. Olivry and Miss S. Balu for help with the artwork and the preparation of this manuscript, respectively.

\section{References}

Applegate LA and Frenk E (1995) Oxidative defense in cultured human skin fibroblasts and keratinocytes from sun-exposed and non-exposed skin. Photodermatol. Photoimmunol. Photomed. 11: 95-101

Applegate LA, Noël A, Vile G, FrenkE and Tyrrell RM (1995) Two genes contribute to different extents to the heme oxygenase enzyme activity measured in cultured human skin fibroblasts and keratinocytes: implications for protection against oxidative stress. Photochem. and Photobiol. 61: 285-291

Asselineau D, Bernard BA, Bailly C and Darmon M (1985) Epidermal morphogenesis and induction of $67 \mathrm{kD}$ keratin polypeptide by culture at the liquide-air interface. Exp. Cell Res. 159: 536-539

Asselineau D, Bernard BA, Bailly C and Darmon M (1989) Retinoic acid improves epidermal morphogenesis. Dev. Biol. 133: 322-335

Asselineau D and Darmon M (1995) Retinoic acid provokes metaplasia of epithelium formed in vitro by adult human epidermal keratinocytes. Differentiation 58: 297 306

Bernerd F and Asselineau D (1997) Successive alteration and recovery of epidermal differentiation and morphogenesis after specific UVB-damages in skin reconstructed in vitro. Dev. Biol. 183: 123-138

Bernstein EF, Chen YQ, Kopp JB, Fisher L, Brown DB, Hahn PJ, Robey FA Lakkakorpi J and Uitto J (1996) Long-term sun exposure alters the collagen of the papillary dermis. J. Am. Acad. Dermatol. 34: 209-218.

Boyer B, Fourtanier A, Kern P and Labat-Robert J (1992) UVA- and UVB-induced changes in collagen and fibronectin biosynthesis in the skin of hairless mice. J. Photochem. Photobiol. B: Biol. 14: 247-259

Chen VL, Fleischmajer R, Schwartz E, Palaia M and Timpl R (1986) Immunochemistry of elastotic material in sun-damaged skin. J. Invest. Dermatol. 87, 334-337

Clark R (1991) Cutaneous wound repair. In Physiology, biochemistry and molecular biology of the skin. (Goldsmith L.A. Ed.) 2nd Ed, pp. 576-601. Oxford University Press, New York

Coulomb B, Dubertret L, Bell E, Merrill C, Fosse M, Breton-Gorius J, Prost C and Touraine R (1983) Endogenous peroxidases in normal human dermis: a marker of fibroblast differentiation. J. Invest. Dermatol. 81:75-78
Djavaheri-Mergny M, Mazière C, Santus R, Dubertret L and Mazière JC (1994) Ultraviolet $A$ decreases epidermal growth factor (EGF) processing in cultured human fibroblasts and keratinocytes: inhibition of EGF-induced diacylglycerol formation. J. Invest. Dermatol. 102, 192-196

Drobetsky EA, Turcotte J and Châteauneuf A (1995) A role for Ultraviolet A in solar mutagenesis. Proc. Natl. Acad. Sci. USA 92: 2350-2354

Fisher GJ, Datta SC, Talwar HS, Wang ZQ, Varani J, Kang S and Voorhees JJ (1996) Molecular basis of sun-induced premature skin ageing and retinoid antagonism. Nature 379: $335-339$

Freeman SE, Gange RW, Sutherland JC, Matzinger EA and Sutherland BM (1987) Production of pyrimidine dimers in DNA of human skin exposed in situ to UVA radiation. J. Invest. Dermatol. 88: 430-433

Freeman SE, Hacham H, Gange RW, Maytum DJ, Sutherland JC and Sutherland BM (1989) Wavelength dependence of pyrimidine dimer formation in DNA of human skin irradiated in situ with ultraviolet light. Proc. Natl. Acad. Sci. USA 86: 5605 5609

Fuchs E (1996) Keratins: mechanical integrators in the epidermis and hair and their role in disease. Prog. Dermatol. 30: 1-12

Gaboriou F, Morlière P, Marquis I, Moysan A, Geze M and Dubertret L (1993) Membrane damage induced in cultured human skin fibroblasts by UVA irradiation. Photochem. Photobiol. 98: 515-520

Gilchrest BA (1989) Dermatoheliosis (Sun-induced aging). In Skin and Aging Processes. (Gilchrest B.A. Ed.), pp. 97-116. CRC Press

Hanson D and DeLeo V (1990) Long-wave ultraviolet light induces phospholipase activation in cultured human epidermal keratinocytes. J. Invest. Dermatol. 95 $158-163$

Kligman L (1995) Animal models of photodamage and its treatment. In: Photodamage (Gilchrest B.A. Ed.) Chap. 9, pp. 136-156. Blackwell Science Inc. USA

Kligman L, Akin FJ and Kligman AM (1982) Prevention of ultraviolet damage to the dermis of hairless mice by sunscreens. J. Invest. Dermatol. 78: 181-189

Kligman L, Chen HD and Kligman AM (1984) Topical retinoic acid enhances the repair of ultraviolet damaged dermal connective tissue. Conn. Tiss. Res. 12: 139-150

Kligman L, Akin FJ and Kligman AM (1985) The contributions of UVA and UVB to connective tissue damage in hairless mice. J. Invest. Dermatol. 84: 272-276

Lavker RM (1995) Cutaneous aging: chronologic versus photoaging. In Photodamage. (Gilchrest B.A. Ed.), pp. 123-135. Blackwell Science, Cambridge, USA

Lavker RM and Kligman AM (1988) Chronic heliodermatitis: a morphologic evaluation of chronic actinic dermal damage with Emphasis on the role of mast cells. J. Invest. Dermatol 90: 325-330

Lavker RM, Gerberick GF, Veres DA, Irwin CJ and Kaidbey KH (1995a) Cumulative effects from repetitive exposures to suberythemal doses of UVB and UVA in human skin. J. Am. Acad. Dermatol. 32: 53-62

Lavker RM, Veres DA, Irwin CJ and Kaidbey KH (1995b) Quantitative assessment of cumulative damage from repetitive exposures to suberythemogenic doses of UVA in human skin. Photochem. Photobiol. 62: 348-352

Lazarides E (1982) Intermediate filaments: a chemically heterogeneous, developmentally regulated class of proteins. Ann. Rev. Biochem. 51: 219-250

Lowe NJ, Meyers DP, Wieder JM, Luftman D, Borget T, Lehman MD, Johnson AW and Scott IR (1995) Low doses of repetitive ultraviolet A induce morphologic changes in human skin. J. Invest. Dermatol. 105: 739-743

Magnaldo T, Bernerd F, Asselineau D and Darmon M (1992) Expression of loricrin is negatively controlled by retinoic acid in human epidermis reconstructed in vitro. Differentiation 49: 39-46

Morlière P, Moysan A, Santus R, Hüppe G, Mazière JC and Dubertret L (1991) UVA induces lipid peroxydation in cultured human fibroblasts. Biochem. Biophys Acta 1084: 261-268

Moysan A, Clément-Lacroix P, Michel L, Dubertret L and Morlière P (1995) Effects of ultraviolet $A$ and antioxidant defense in cultured fibroblasts and keratinocytes. Photodermatol. Photoimmunol. Photomed. 11: 192-197

Niggli HJ and Applegate LA (1997) Glutathione response after UVA irradiation in mitotic acid and postmitotic human skin fibroblasts and keratinocytes. Photochem. Photobiol. 65: 680-684

Nusgens B, Merrill C, Lapière C and Bell E (1984) Collagen biosynthesis by cells in a tissue equivalent matrix in vitro. Collagen Rel Res. 4: 351-364

Oikarinen A, Karvonen J, Uitto J and Hannuksela M (1985) Connective tissue alterations in skin exposed to natural and therapeutic UV-radiation. Photodermatology 2: 15-26 
Peak MJ, PeakJG and Carnes BA (1987) Induction of direct and indirect single-strand breaks in human cell DNA by far-and near-ultraviolet radiations: action spectrum and mechanisms. Photochem. Photobiol. 45: 381-387

Peak JG and Peak MJ (1991) Comparison of initial yields of DNA-to-protein crosslinks and single-strand breaks induced in cultured human cells by far- and near-ultraviolet light, blue light and X-rays. Mut. Res. 246: 187-191

Petersen M, Hamilton T and Li H (1995) Regulation and inhibition of collagenase expression by long-wavelength ultraviolet radiation in cultured human skin fibroblasts. Photochem. Photobiol. 62: 444-448

Reichert U, Michel S and Schmidt R (1993) The cornified envelope: a key structure of terminally differentiating keratinocytes. In The keratinocyte. Molecular Biology of the Skin. (Darmon M. and Blumenberg M. Eds.), pp. 107-150. Academic Press Inc. New York

Rheinwald JG and Green H (1975) Serial cultivation of strains of human keratinocytes: the formation of keratinizing colonies from single cells. Cell 6 : $331-343$

Robert C, Muel B, Benoit A, Dubertret L, Sarasin A and Stary A (1996) Cell surviva and shuttle vector mutagenesis induced by ultraviolet $A$ and ultraviolet $B$ radiation in a human cell line. J. Invest. Dermatol. 106, 721-728

Roza L, van Der Wulp KJM, MacFarlane SJ, Lohman PHM and Baan RA (1988) Detection of cyclobutane thymine dimers in DNA of human cells with monoclona antibodies raised against a thymine dimer-containing tetranucleotide. Photochem. Photobiol. 48: 627-633

Roza L, de Gruijl FR, Bergen Henegouwen JBA, Guikers K, van Weelden H, van Der Schans GP and Baan RA (1991) Detection of photorepair of UV-induced thymine dimers in human epidermis by immunofluorescence microscopy. J. Invest Dermatol. 96: 903-907

Sawamura D, Ohta T, Hanada K, Ishikawa H, Tamai K, Yazima H, Meng X, Nomura K, Hashimoto I, Mauviel A and Uitto J (1996) Involvement of the AP-1 site within the $5^{\prime}$-flanking region of the stromelysin-1 gene in induction of the gene expression by UVA irradiation. Arch. Dermatol. Res. 288: 628-632

Scharffetter K, Wlaschek M, Hogg A, Bolsen K, Schothorst A, Goerz G, Krieg T and Plewig G (1991) UVA irradiation induces collagenase in human dermal fibroblasts in vitro and in vivo. Arch. Dermatol. Res. 283: 506-511

Scharffetter-Kochanek K, Wlaschek M, Briviba K and Sies H (1993) Singlet oxygen induces collagenase expression in human skin fibroblasts. Federation of European Biochemical Societies 331: 304-306
Schwartz E and Kligman L (1995) Topical tretinoin increases tropoelastin and fibronectin content of photoaged hairless mouse skin. J. Invest. Dermatol. 104: 518-522

Steinert PM and Marekov LN (1995) The proteins elafin, filaggrin, keratin intermediate fimalents, loricrin, and small proline-rich proteins 1 and 2 are isodipeptide cross-linked components of the human epidermal cornified cell envelope. J. Biol. Chem. 270: 17702-17711

Tyrrell RM and Pidoux M (1989) Singlet oxygen involvement in the inactivation of cultured human fibroblasts by UVA (334 nm, $365 \mathrm{~nm}$ ) and near visible (405 nm) radiation. Photochem. Photobiol. 49: 407-412

Tyrrell RM and Keyse SM (1990) New trends in photobiology. The interaction of UVA radiation with cultured cells. J. Photochem. Photobiol. B: Biol. 4: 349-361

Vile $G$ and Tyrrell R (1993) Oxidative stress resulting from ultraviolet A irradiation of human skin fibroblasts leads to a heme oxygenase-dependent increase in ferritin. J. Biol. Chem. 268: 14678-14681

Warren R, Gartstein V, Kligman AM, Montagna W, Allendorf RA and Ridder GM (1991) Age, sunlight, and facial skin: a histologic and quantitative study. J. Am. Acad. Dermatol. 25: $751-760$

Werner S, Peters KG, Longaker MT, Fuller-Pace F, Banda MJ and Williams LT(1992) Large induction of keratinocyte growth factor expression in the dermis during wound healing. Proc. Natl. Acad. Sci. 89: 6896-6900

Wlaschek M, Heinen G, Poswig A, Schwarz A, Krieg T and Scharffetter-Kochanek K (1994) UVA-induced autocrine stimulation of fibroblast-derived collagenase/ MMP-1 by interrelated loops of interleukin-1 and interleukin-6. Photochem. Photobiol. 59: 550-556

Wlaschek M, Briviba K, Stricklin G, Sies H and Scharffetter-Kochanek K (1995) Singlet oxygen may mediate the ultraviolet A-induced synthesis of interstitial collagenase. J. Invest. Dermatol. 104: 194-198

Yaar M and Gilchrest BA (1995) Biochemical and molecular changes in photoaged skin. In: Photodamage (Gilchrest B.A. Ed.) Chap. 11, pp 168-184. Blackwell Science Inc. USA

Young AR (1987) The sunburn cell. Photodermatol 4: 127-134 